
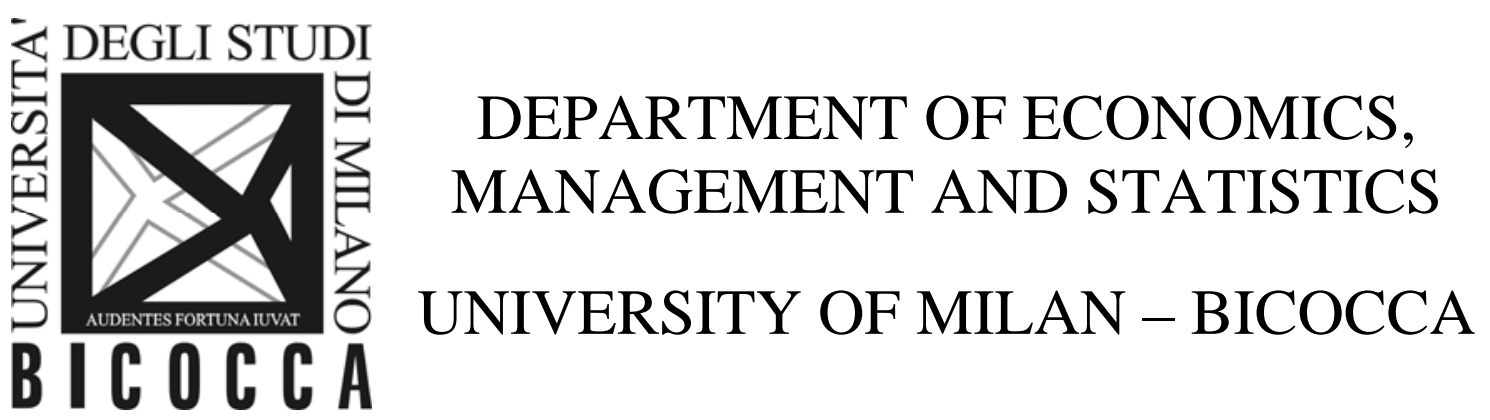

DEMS WORKING PAPER SERIES

\title{
Joint Ventures and the Property Rights Theory of the Firm: a Review of the Literature
}

Valeria Gattai, Piergiovanna Natale

No. 287 - December 2014

Dipartimento di Economia, Metodi Quantitativi e Strategie di Impresa Università degli Studi di Milano - Bicocca 


\title{
Joint Ventures AND the Property Rights TheORY OF THE FiRM: A REVIEW OF THE LITERATURE*
}

\author{
Valeria Gattai and Piergiovanna Natale \\ Università di Milano-Bicocca
}

This version

29 November 2014

\begin{abstract}
Joint ventures (JVs) are a very common form of inter-firm collaborations and, not surprisingly, the object of a vast literature, spanning from economics to management and business studies. Issues of control are central to the definition of JV, which naturally begs an interpretation in the context of the property rights theory (PRT) of the firm. In a series of seminal papers, Grossman, Hart and Moore (GHM) offer a rigorous framework to predict the allocation of control rights. Notably, under the standard assumptions of GHM, JVs are suboptimal. However, JVs are not suboptimal in more general settings where some of the original framework's assumptions are relaxed. In the context of the PRT, this paper surveys more than 20 contributions that deal with the optimality of JVs under contract incompleteness. Questioning GHM's assumptions, the authors of these contributions unveil relevant circumstances in which JV outperforms sole ownership. Despite contributions being scattered over time and bibliographical space, we believe enough material has accumulated over 25 years of economic modelling to encourage some systematization. The discussion is organized in an intuitive and non-technical way; particular effort is devoted to analyse each contribution in detail and to provide a unitary framework.
\end{abstract}

JEL: D23; L24

Keywords: Incomplete contracts; Property rights; Joint venture; Joint control; Joint ownership

\footnotetext{
* The authors are grateful to Ferdinando Colombo and Mario Gilli for helpful comments and insightful discussions. Financial support from Università di Milano-Bicocca and CISEPS is gratefully acknowledged. All remaining errors are the authors’ own.
} 


\section{INTRODUCTION}

In the class of ownership contracts analyzed [in GHM], property rights matter only to the extent that there exist (viable) outside opportunities...there is no outside opportunity and so no way to improve on joint ownership. Maskin and Tirole (1999, p. 142-143)

This paper focuses on the contribution of the property rights theory (PRT) of the firm to our understanding of joint ventures (JVs).

According to Zephyr (2014), more than 24,000 joint venture agreements have been signed since the early 1990s, and despite the post-crisis turmoil, approximately 3,000 were announced in 2013 - a notable 15\% increase over the previous year. Joint ventures spread worldwide, from Far East and Central Asia (55\%) to Europe (22\%), North America (10\%), South and Central America (6\%), the Middle East (3\%), Africa (2\%), and Oceania (2\%). Furthermore, JVs feature prominently among deals in many sectors, including manufacturing (26\%), finance (15\%), wholesale and retail trade (10\%), legal, accounting and engineering activities (10\%), construction (9\%), and information and communication services (8\%). ${ }^{1}$ This evidence and previous works (e.g., Hagedoorn, 1996, 2002; Caloghirou et al., 2003; Moskalev and Swensen, 2007) show that joint ventures are indeed a very common form of inter-firm collaborations and, unsurprisingly, the object of a vast literature, spanning from economics to management and business studies.

The distinctive feature of a joint venture - maintained across the various strands - is that it involves share-holding in a business entity having the following characteristics: first, the entity is established by a contractual arrangement whereby two or more parties contribute resources towards the business undertaking; second, the parties have joint control over one or more activities carried out according to the terms of the arrangement, and none of the individual investors is in a position to unilaterally control the venture (UNCTAD, 2014). Issues of control are thus central to the definition of joint ventures, which naturally begs an interpretation in the context of the property rights theory of the firm (PRT). This context offers a rigorous framework for predicting the allocation of control (Grossman and Hart, 1986; Hart and Moore, 1990). According to the PRT, a firm is a collection of assets and property rights or residual rights of control confer their holder full discretion over the usage of those assets under any condition not specified in an initial contract. Drawing on the crucial assumption of contract incompleteness - i.e., the parties' inability to specify in an enforceable contract which actions they should take in any contingency that affects their contractual relationship - the allocation of control rights becomes a very sensitive issue. The occurrence of gaps, missing provisions and ambiguities in contracts paves the way for opportunistic behaviour, which, in turn, induces parties to incur costly self-protection actions. To limit the

\footnotetext{
${ }^{1}$ Authors' elaborations from Zephyr (2014) data on joint ventures completed in 2013.
} 
adverse effects of contract incompleteness, parties allocate residual rights of control, giving rise to two alternative classes of ownership regimes: unilateral control and joint control. Under the former, control rights are assigned to one partner, who can then grant or deny to the other party access to the assets; under the latter, residual rights are conferred on each partner, which gives each partner a veto power over the use of the assets. JVs appear to be consistent with the PRT definition of joint control. ${ }^{2}$ However, under the standard assumptions of the Grossman-Hart-Moore (GHM) framework, JVs are proved to be suboptimal. In other words, even though the PRT seems to be the most natural framework to study joint ventures and to justify their widespread diffusion, the theory itself leaves no room for JVs.

To understand ${ }^{3}$ why JVs are suboptimal, consider two partners cooperating on a production project that requires the use of an asset and ex-ante non-contractible relationship-specific investments. As long as the marginal return to investment depends on access to the asset, the allocation of property rights shapes the parties' incentive to invest. Because of contract incompleteness, parties negotiate over the division of the trade surplus after investments are sunk. Suppose negotiation over the division of the surplus fails. The partner in control of the asset can deny the other access to it, thereby acquiring substantial bargaining power over the division of the surplus. This reduces the incentive to invest by the non-controlling party while enhancing the incentive to invest by the controlling one. This trade-off in investments drives the main predictions of the approach. In a regime of sole ownership, control rights are assigned to the partner whose investment matters the most in generating the surplus. On the contrary, joint control deprives both partners of control rights, thus resulting in significant underinvestment with respect to sole ownership. Underinvestment is the exact reason why joint ventures are suboptimal under the standard set of GHM assumptions, which casts a shadow over the predictive power of the property rights theory of the firm. However, joint ventures need not be suboptimal if one removes (at least one of) the original hypotheses. Some authors, who started to question the original assumptions of the GHM approach, have made attempts of this sort from time to time. Each author focuses on one assumption at a time and unveils interesting circumstances under which joint control outperforms sole ownership. It would be inappropriate to say that they created a body of literature, as most contributions appear to be quite apart from one another. They are apart from a chronological point of view, as some contributions date back to the 1990s and others have appeared in the past few years; they are also apart from a bibliographical point of view, as cross-citations tend to be quite infrequent. Nonetheless, we believe enough material has been accumulated over 25 years of economic modelling to warrant attention and encourage some systematization. Moreover, a careful

2 Consistently with UNCTAD (2014), we consider “joint control”, “joint ownership” and “joint venture” as synonymous.

${ }^{3}$ For a full discussion of the GHM framework, see Section 2. 
inspection of existing studies reveals some regularities, which thus advocate for a unifying framework.

In light of the discussion above, the present paper surveys more than 20 papers that prove the optimality of joint ventures under contract incompleteness, in the context of the property rights theory of the firm. To the best of our knowledge, this issue has been primarily analysed from a theoretical point of view; therefore, our survey is mostly concerned with theoretical aspects. However, when empirical evidence is available, it is discussed and compared with the models' testable predictions ${ }^{4}$.

In reviewing this class of papers, we aim to provide some complementary insights alongside existing surveys on related topics. As in Kogut (1988), Lyons (1991), Werner (2002) and Caloghirou et al. (2003), our primary focus is on joint ventures, within the wide array of inter-firm collaborations; as in Foss et al. (2000), Williamson (2002), Gibbons (2005), Lafontaine and Slade (2007), Aghion and Holden (2011), Segal and Whinston (2012) and Walker (2013, 2014), we take a theory of the firm perspective and move within the PRT framework; as in Salanie (1997), Hart (1995), Tirole (1999), Martimort et al. (2005), Schmitz (2001) and Fares (2006), we consider contributions that share the crucial assumption of contract incompleteness. Nevertheless, this paper should not be regarded as a survey on contract theory, nor on the theory of the firm; similarly, we do not aim to provide a general overview of joint venture studies. These goals have already been achieved quite successfully in the aforementioned papers.

The novelty of the present review — if any — lies in combining the three tiles of JV, PRT and contract incompleteness into an original mosaic that reverses the general wisdom, according to which joint ownership is suboptimal. Each of these tiles has already been analysed in previous surveys on related topics, but only in isolation. In this review, we are able to draw some complementary results that arise from the combination of JV, PRT and contract incompleteness into a unitary framework.

Our tentative road map, across the 24 papers we review, is as follows. First, we present the GHM framework and discuss the standard list of assumptions that deliver the famous result about the suboptimality of joint control. Second, we show how this result has been reversed, by generally removing one assumption at a time. For expositional convenience, we group the surveyed papers into three sections that deal with the three stages of the GHM game: trade, investment and

\footnotetext{
${ }^{4}$ As remarked in Lafontaine and Slade (2007), few studies aim at testing the predictions from the property rights theory of the firm, in comparison to the large number of contributions attempting to validate those from moral hazard and transaction cost models. This has largely to do with lack of appropriate micro data. See also Williamson (2002) on this issue.
} 
allocation of property rights. ${ }^{5}$ Then, subsections clarify which assumption has been altered for each stage of the game and comment on the main results. Without claiming to be a complete picture, Figure 2 displays our road map in a stylized diagram. The discussion is organized in an intuitive and non-technical way to win the favour of a large audience. More formal material can be found in the endnotes. To help the reader focus on the most relevant issues, sections end with a brief summary — titled "In a nutshell" — that includes the reasons why joint ownership outperforms sole ownership when departing from GHM in a particular way.

The rest of the paper is organized as follows. In Section 2, we present the main elements and predictions of the property rights theory of the firm, in the original spirit of Grossman and Hart (1986) and Hart and Moore (1990). In Section 3, we discuss all contributions that depart from GHM in terms of the assumptions about the nature of investment. In Section 4, we present those dealing with the problem of ex-post bargaining. In Section 5, we present those questioning the allocation of property rights itself. Section 6 concludes and suggests future lines of research.

\section{THE COSTS AND BENEFITS OF INTEGRATION: THE GHM APPROACH}

As with Hart (1995), consider two firms, each run by a manager. Firm 1 produces a final good, transforming an input (e.g., a widget) by means of asset $a_{1}$. Firm 2 produces widgets by means of asset $a_{2} \cdot M_{1}$ and $M_{2}$ - the managers of firm 1 and 2, respectively - anticipate that they will benefit from trading a widget at some time in the future. They are also aware that they can enlarge the trade surplus by currently undertaking costly actions to improve the final good's marketability or to increase the widget's reliability. Still, they are unable to commit to undertaking the costly actions or to trading at an agreed upon price in the future. To do so, a contract is required to detail the investments to be undertaken or describe the exact features the widget should possess and the price at which it should be traded. Writing and enforcing such a contract is generally unfeasible. ${ }^{6}$ It follows that contracts are incomplete, exposing parties to the risk of opportunistic behaviour and hold-up problems. In fact, parties select investments non-cooperatively, and they negotiate over the widget's price only after investments are sunk. The redistribution of surplus entailed by the negotiation over the widget's price has an adverse effect on the incentive to undertake the investments, and efficiency losses ensue. GHM argue that efficiency losses can be remedied by

\footnotetext{
${ }^{5}$ This clearly implies some discretion by the authors, since some contributions saddle on more than one section. For the sake of completeness, when this is the case, we proceed as follows. We discuss the paper in all sections to which it can be ascribed; in addition, we stress where, in our view, its most notable contribution lies.

${ }^{6}$ When the features of the widget or the nature of the investments are not well defined at the time of contracting, the contract must specify which course of action each party should undertake in any foreseeable contingency relevant for their relationship. A state contingent contract is costly to compile and for its very nature difficult to enforce as a court may find it hard to verify which contingency applies. It follows that parties deliberately omit clauses covering events they consider unlikely or of no consequences as well as events a third party is unable to verify. For an in-depth discussion of incomplete contracts, the reader is referred to Hart (1995) and Salanie (1997).
} 
appropriately conferring ownership rights for assets $a_{1}$ and $a_{2}$. To see why this is the case, we need to add some structure to the scenario above. The assumptions at the core of the GHM approach are reported in italics. This italicized text helps the reader to focus attention on the very elements that have been questioned in the surveyed contributions and according to which the discussion in the following sections is organized.

As displayed in Figure 1, events unfold in the following three stages. At $t=1, M_{1}$ and $M_{2}$ meet and select an ownership regime. At $t=2, M_{1}$ and $M_{2}$ make simultaneous and independent investment choices. At $t=3$, the parties bargain over the price at which the widget should be traded.

\section{[Insert Figure 1 about here]}

Ownership confers residual control rights over assets, i.e., it confers "the right to decide how these assets are to be used except to the extent that particular usages have been specified in an initial contract.” (Hart and Moore, 1990, p. 1120). Given two assets and two managers, we have four ownership regimes:

Non-integration $\left(A_{N I}\right): M_{1}$ owns $a_{1}$, and $M_{2}$ owns $a_{2}$.

Type 1 integration $\left(A_{1}\right)$ : $M_{1}$ owns $a_{1}$ and $a_{2}$.

Type 2 integration $\left(A_{2}\right): M_{2}$ owns $a_{1}$ and $a_{2}$.

Joint control ( $A_{J C}$ ): both $M_{1}$ and $M_{2}$ have a veto power over the use of $a_{1}$ and $a_{2}{ }^{7}$

To identify the optimal allocation of control rights, we study first how parties bargain and invest, given the allocation of control rights, and then establish which ownership regime delivers the largest surplus. ${ }^{8}$

To Trade OR Not to Trade. As mentioned above, Firm 1 produces a final good by means of asset $a_{1}$ and a widget. Even if he has control of $a_{2}, M_{1}$ is unable to operate it; therefore, to produce a widget, he needs the cooperation of $M_{2}$. It follows that no matter the ownership structure, $M_{1}$ bargains with $M_{2}$ over the widget's price. If negotiation breaks down, $M_{1}$ enlists some other supplier. The same holds true for $M_{2}$. He bargains with $M_{1}$; if no agreement is reached, he offers his services on the market. Bargaining is efficient. It occurs under symmetric information, and the trade surplus is shared according to the Nash bargaining solution.

INVESTMENT. Revenue from marketing the final good increases in some investment $e_{1}$ undertaken at cost $C_{1}\left(e_{1}\right)$ by $M_{1}$ well in advance of production, i.e., before reaching an agreement

\footnotetext{
${ }^{7}$ Some authors refer to a regime in which both parties have veto power on the use of assets as collective ownership. See Rajan and Zingales (1998).

${ }^{8}$ In the language of game theory, we are solving the game between $M_{1}$ and $M_{2}$ by backward induction.
} 
with $M_{2}$ or any other supplier. Likewise, the widget's reliability increases in some action $e_{2}$, to be undertaken at cost $C_{2}\left(e_{2}\right)$ by $M_{2}$ before having reached an agreement over the widget's price with $M_{1}$ or any other producer. $M_{1}$ and $M_{2}$ invest simultaneously. The investment is in human capital. Investment being in human capital, parties have no access to each other's investment if they fail to trade. The investment that $M_{i}$ undertakes thus has no effect on $M_{j}$ 's outside option and we say that there are no investment spillovers across outside options. Moreover, the investment is made only once. Parties may expect to trade repeatedly, but further investment does not increase the trade surplus. The overall benefit from investment is sensitive to the identities of the trading partners. No matter the ownership regime, the joint surplus that $M_{1}$ and $M_{2}$ obtain by trading with each other exceeds the total surplus from any other relationship that they may undertake separately. Investment is relationship-specific. Relationship-specificity applies to total and marginal return from investments. ${ }^{9}$ The same investment that affects the surplus from trading within the relationship increases the surplus from trading outside the relationship. The marginal benefit of investment outside the relationship is sensitive to the number of assets a party controls. In particular, it is nondecreasing in the number of assets a party controls, which captures the assumption that assets are either complementary or independent and never substitutes. When assets are complementary, the marginal benefit of investment by party $i$ is the greatest under type $i$ integration. When they are independent, the marginal benefit of party $i$ 's investment is the same under non-integration and type $i$ integration. The marginal benefit of investment is lowest when the party controls no asset.

Allocation of Property Rights. Parties meet and cooperatively select the ownership regime. Managers suffer no liquidity constraints, and they can thus transfer assets between themselves to maximise the total surplus from producing the final good. Ownership regimes are unconditional; parties cannot hold options to buy or sell control rights. Ownership jointly confers control rights and residual rights on income; residual rights on income and control rights cannot be decoupled. The party that holds control rights is the residual claimant of any income that is generated by means of the assets.

The allocation of property rights has efficiency implications, as it affects a party's outside option and thereby his incentive to invest. The division of trade surplus occurs according to the Nash bargaining solution. If an agreement is reached, each party receives his outside option plus a share of the extra surplus that the parties obtain from trading with each other rather than on the market. $S=R_{1}\left(e_{1}\right)+Q\left(e_{2}\right)$ is the joint surplus from $M_{1}$ and $M_{2}$ trading with each other. Taking into account that assets ownership affects the return of investment outside the relationship, we call

\footnotetext{
${ }^{9}$ Note that investment in human capital is a sufficient condition for relationship-specificity to hold across ownership regimes.
} 
$r\left(e_{1} ; A_{i}\right)$ the value of the outside option for $M_{1}$ and $q\left(e_{2} ; A_{i}\right)$ the value of the outside option for $M_{2}$ under ownership regime $i$. Note that $R_{1}\left(e_{1}\right)$ and $Q\left(e_{2}\right)$ are not conditional on the ownership regime. In fact, parties can access all assets when trading with each other. Under the assumption of equal bargaining power, ${ }^{10}$ the parties’ net payoffs are as follows:

$$
\begin{gathered}
\pi_{1}\left(A_{i}\right)= \\
r\left(e_{1} ; A_{i}\right)+\frac{1}{2}\left\{\left[R\left(e_{1}\right)+Q\left(e_{2}\right)\right]-\left[r\left(e_{1} ; A_{i}\right)+q\left(e_{2} ; A_{i}\right)\right]\right\}-C_{1}\left(e_{1}\right)= \\
\frac{1}{2}\left[R\left(e_{1}\right)+Q\left(e_{2}\right)\right]+\frac{1}{2} r\left(e_{1} ; A_{i}\right)-\frac{1}{2} q\left(e_{2} ; A_{i}\right)-C_{1}\left(e_{1}\right) \\
\pi_{2}\left(A_{i}\right)= \\
q\left(e_{2} ; A_{i}\right)+\frac{1}{2}\left\{\left[R\left(e_{1}\right)+Q\left(e_{2}\right)\right]-\left[r\left(e_{1} ; A_{i}\right)+q\left(e_{2} ; A_{i}\right)\right]\right\}-C_{2}\left(e_{2}\right)= \\
\frac{1}{2}\left[R\left(e_{1}\right)+Q\left(e_{2}\right)\right]+\frac{1}{2} q\left(e_{2} ; A_{i}\right)-\frac{1}{2} r\left(e_{1} ; A_{i}\right)-C_{2}\left(e_{2}\right)
\end{gathered}
$$

It is easy to see that ex-ante investments are suboptimal, no matter the ownership regime. Both $M_{1}$ and $M_{2}$ attach a weight of only $1 / 2$ to the total surplus from trade with each other. As the marginal return of investment is higher within the relationship than outside it (i.e., relationship-specificity holds for the total and marginal return from investment), both parties underinvest. Still, ownership regimes are not all equally inefficient. The ownership regime affects investment and thus the trade surplus through its impact on outside options. Asset complementarity implies that the more assets a manager controls, the larger the effect of investment on his outside option and incentive to invest. ${ }^{11}$ It follows that shifting ownership across parties changes the total trade surplus $S$ via two effects: it increases the incentive to invest by the party acquiring control and reduces the incentive to invest by the party losing control. The ranking of ownership regimes depends on the sensitivity of the total trade surplus to each party’s ex-ante investment.

As the title of Grossman and Hart's (1986) seminal paper makes clear, the property rights theory of the firm identifies the trade-off at the heart of the integration decision and shies away from providing an a-priori ordering of ownership regimes. Still, a partial a-priori ordering appears to be embedded in this theory. As is standard in the literature, assume that relationship-specificity applies to the total and marginal returns from investment. ${ }^{12}$ All ownership regimes suffer from underinvestment, and a regime of joint control cannot be preferred to non-integration or type $i$ integration. Suppose type $i$ integration is preferred to non-integration. In this case, the increase in party i's investment more than compensates for the decrease in party $j$ 's investment in generating

\footnotetext{
${ }^{10}$ This assumption is standard in the PRT literature, with the only exception of Schmitz (2013a).

${ }^{11}$ Formally, $r^{\prime}\left(e_{1} ; a_{1} ; a_{2}\right) \geq r^{\prime}\left(e_{1} ; a_{1}\right) \geq r^{\prime}\left(e_{1}\right)$ and $q^{\prime}\left(e_{2} ; a_{1} ; a_{2}\right) \geq q^{\prime}\left(e_{2} ; a_{2}\right) \geq q^{\prime}\left(e_{2}\right)$.

12 That is: $R\left(e_{1}\right)+Q\left(e_{2}\right)>r\left(e_{1} ; A_{i}\right)+q\left(e_{2} ; A_{i}\right) ; R^{\prime}\left(e_{1}\right)>r^{\prime}\left(e_{1} ; A_{i}\right) ; Q^{\prime}\left(e_{2}\right)>q^{\prime}\left(e_{2} ; A_{i}\right), \forall A_{i}$.
} 
total surplus $S$. A regime of joint control cannot do better than type $i$ integration, as the marginal benefit of investment that stems from one's outside option does not change for party $j$ and decreases for party i. Likewise, a regime of joint control cannot outperform non-integration if the latter is preferred to type $i$ integration. Non-integration is preferred when both parties' investments are important for generating surplus $S$. With respect to type $i$ integration, joint control would reduce the owner's incentive to invest and leave unaffected the non-owner's incentive to invest; thus, it cannot outperform non-integration.

In its standard version, the GHM model has no room for joint ownership; asset ownership motivates, and joint control can never be optimal as long as underinvestment is the only inefficiency.

\section{THE NATURE OF INVESTMENT}

The predictions of the GHM approach rest on the sensitivity of the parties' payoff to investment. In this section we ask: how much of this sensitivity depends on the assumptions that GHM make about investment? The answer to this question is central to a number of contributions to the property rights theory of the firm, which provide a rationale for joint control.

Investment Spillovers: Human vs. Physical Capital. As mentioned above, in the original GHM framework, there are no investment spillovers; party i's outside option is independent of party j's investment. This is consistent with the assumption that the investment is in human capital; party $i$ can benefit from party $j$ 's investment only when trading with him. Let us suppose instead that party $j$ 's investment is partially embedded in some physical asset. Controlling such an asset allows party $i$ to benefit from party $j$ 's investment, even in the event of ex-post disagreement. ${ }^{13}$ This strengthens party i's bargaining position, and, as a consequence, it weakens party j's incentive to invest.

Hart (1995) shows that there are circumstances under which the described effects make joint control optimal. Suppose that the production of the final good requires a widget. Production of a widget in turn, requires the use of one asset or a group of strictly complementary assets, which we will call $a$. With just one asset, there are only three ownership regimes to consider: type 1 and type 2 integration, in which either $M_{1}$ or $M_{2}$ owns $a$, and joint control. The efficiency ranking of regimes can be reduced to order type 1 and type 2 integration and to compare the largest surplus that either of them delivers with the surplus from joint control. For expositional convenience, let us

\footnotetext{
${ }^{13}$ Note that this holds true also for party $j$ 's investment embedded in intangible assets such as a brand. The argument in favour of joint control thus extends beyond the case of physical assets.
} 
assume that type 1 dominates type 2 integration. ${ }^{14}$ Abandoning type 1 integration in favour of joint control reduces $M_{1}$ 's investment, but it fosters $M_{2}$ 's investment. Under type 1 integration, $M_{2}$ 's investment positively affects $M_{1}$ 's outside option, and it reduces $M_{2}$ 's marginal benefit from investment. Under joint control, $M_{1}$ cannot use the asset without the consent of $M_{2}$. Embedded in the asset, $M_{2}$ 's investment has no positive effect on $M_{1}$ 's outside option, and it thus has no adverse effect on his own payoff. As long as the ensuing increase in $M_{2}$ 's investment raises the total surplus more than the decrease in $M_{1}$ 's investment reduces it, joint control dominates type 1 integration. Unfortunately, the optimality of joint control does not hold in the case of two or more assets, i.e., when the set of ownership regimes includes non-integration. Suppose $M_{1}$ produces the final good by asset $a_{1}$ and a widget, while $M_{2}$ produces widgets by asset $a_{2}$. Managers specialize their investment to just one asset so that $M_{i}$ can only benefit from $M_{j}$ 's investment if he has control of $a_{j}$. Type $i$ integration is affected by the same investment distortions emphasized in the case of one asset. Still, with two assets, non-integration is a superior remedy than joint control for such distortions. As with joint control, non-integration neutralizes investment cross-effects, but it also preserves the incentive to invest that stems from one's outside option. It follows that introducing investment in physical capital does not alter the partial ordering of the GHM approach; joint control can only be optimal if non-integration is not viable.

However, there is more to introducing investment in physical capital than meets the eye. Allowing for investment in physical capital opens the door to spillovers across outside options ${ }^{15}$ and thus to the possibility of an overturn of GHM's partial ordering of regimes. In this more general setting, Rosenkranz and Schmitz $(1999,2003)$ restore the optimality of joint control. In Rosenkranz and Schmitz (1999), two parties work on a research project and employ an asset that is an excludable public good, e.g., a patent. The set of ownership regimes includes joint ownership without veto power; each party can use the asset without the consent of the other. As the asset is a public good, joint ownership without veto power is akin to non-integration. Parties invest in human capital and decide how much of their know-how about the effective use of the patent is disclosed to the partner. Disclosure positively affects the trade surplus within the relationship as well outside it; party i's outside option thus increases with party j's disclosure. Party i's disclosure makes party $j$ more productive in his use of the patent even when he works alone. When disclosure is important in

\footnotetext{
${ }^{14}$ Appropriately modifying expressions (1) and (2), the parties’ payoffs under type 1 integration can be written as $\pi_{1}\left(A_{1}\right)=\frac{1}{2}\left[R\left(e_{1}\right)+Q\left(e_{2}\right)\right]+\frac{1}{2}\left[r\left(e_{1} ; a ; \lambda e_{2}\right)-q\left(e_{2}\right)\right]-C_{1}\left(e_{1}\right)$ and $\pi_{2}\left(A_{1}\right)=\frac{1}{2}\left[R\left(e_{1}\right)+Q\left(e_{2}\right)\right]+\frac{1}{2}\left[q\left(e_{2}\right)-r\left(e_{1} ; a ; \lambda e_{2}\right)\right]-C_{2}\left(e_{2}\right)$,
} where $0 \leq \lambda \leq 1$ captures the degree of investment spillovers.

${ }^{15}$ See de Meza and Lockwood (2004) and Guriev (2003). 
generating the trade surplus within the relationship, joint ownership with veto power dominates both integration and joint ownership without veto power. In a companion paper, Rosenkranz and Schmitz (2003) model a dynamic setting in which ownership is renegotiable over time. In this framework, joint control in the early stages of the game allows the parties to benefit from full disclosure, while ownership is optimally renegotiated to non-integration later in the relationship.

To conclude, GHM rule out investment spillovers across outside options, as investments are in human capital only. As in Hart (1995), introducing investment in physical capital, results in a more general framework, in which spillovers allow the overturning of GHM's partial ordering of regimes. Subsequent contributions show that what matters is whether there are spillovers across outside options, not whether the investment is in human or physical capital. ${ }^{16}$

InVESTMENT RELATIONSHIP-Specificity: What If It Is A MATTER OF ChOICE? In the GHM approach, investing parties consider the effects of their actions on both the trade surplus within the relationship and their outside options. As investment is more productive (in a marginal sense) within the relationship than outside it, parties underinvest, and the suboptimality of joint control follows. Still, the very same objective of improving one's outside option may cause overinvestment, which thus establishes the optimality of joint control.

Cai (2003) shows that joint control can be optimal when parties can choose how much to invest to increase the surplus from trading within the relationship and how much to invest in improving their outside option. As in the standard GHM framework, $M_{1}$ produces a final good by asset $a_{1}$ and a widget, while $M_{2}$ produces widgets by asset $a_{2}$. Ex-ante investment can be specific or general. Specific investment is productive only within the relationship, while general investment is productive within the relationship and outside it. ${ }^{17}$ General investment is overprovided in any ownership regime, ${ }^{18}$ though less so under joint control. Does this make a case for joint control over other ownership regimes? The answer is a qualified yes. Suppose party i's marginal cost of providing specific investment decreases in the amount of general investment. Joint control raises the cost of specific investment with respect to non-integration; thus, the non-integration delivers more specific investment and possibly a larger surplus than joint control. Still, the opposite holds true

\footnotetext{
${ }^{16}$ On this, see also Segal and Whinston (2012).

${ }^{17}$ Under the assumption of multidimensional investment, party $i$ undertakes specific $\left(e_{i}^{S}\right)$ as well as general $\left(e_{i}^{G}\right)$ investment. The parties' payoffs can be written as: $\pi_{1}\left(A_{1}\right)=\frac{1}{2}\left[R\left(e_{1}^{s}\right)+Q\left(e_{2}^{s}\right)\right]+\frac{1}{2}\left[r\left(e_{1}^{G} ; A_{1}\right)-q\left(e_{2}^{G} ; A_{1}\right)\right]-C_{1}\left(e_{1}^{s} ; e_{1}^{G}\right)$ and $\pi_{2}\left(A_{1}\right)=\frac{1}{2}\left[R\left(e_{1}^{s}\right)+Q\left(e_{2}^{s}\right)\right]+\frac{1}{2}\left[q\left(e_{2}^{G} ; A_{1}\right)-r\left(e_{1}^{G} ; A_{1}\right)\right]-C_{2}\left(e_{2}^{s} ; e_{2}^{G}\right)$, respectively.

18 This result is reminiscent of overinvestment as introduced in Grossman and Hart (1986), where relationshipspecificity applies to total but not to marginal benefit from trade. If an increase in investment raises the value of the outside option more than the surplus from trading within the relationship, all ownership regimes are plagued with overinvestment and non-integration is preferred to integration. Note that Grossman and Hart (1986) only consider nonintegration and type $i$ integration and is silent about joint control.
} 
when specific and general investments are substitutes in the cost function. Joint control provides little incentive to undertake wasteful general investment, and it reduces the marginal cost of providing specific investments, thus unambiguously increasing the total trade surplus. This result applies also to the case in which general investment positively affects the trade surplus within the relationship, albeit less than it does for the surplus from trading outside the relationship. ${ }^{19}$

Schmitz (2013b) argues that joint control is too blunt an instrument to limit the adverse effects of the outside option's sensitivity to the parties' investments. Parties invest in physical capital, but they also choose how productive their investment is outside the relationship, i.e., they select the degree of investment relationship-specificity. A high degree of relationship-specificity implies that investment has little impact on outside option. It follows that an appropriate choice of relationship-specificity can mitigate investment spillovers across outside options. Under the assumption that one party's investment is more productive than that of the other, sole ownership by the more productive party dominates joint control. Type $i$ integration preserves for the more productive party the incentive to invest that stems from his outside option, while a high degree of relationship-specificity shelters the less productive party from any adverse effect from his own investment. Schmitz (2013b) argues that ownership regime and relationship-specificity should be selected jointly and cooperatively. Still, in an incomplete contract framework, cooperation on the degree of relationship-specificity may not be easier to achieve than cooperation over ex-ante investments.

Asset Complementarity: What If It FAils? Asset complementarity is a driving force in the GHM approach. When assets are independent, non-integration is optimal. Transferring control of asset $a_{j}$ to party $i$ does not increase party $i$ 's incentive to invest and reduces party j's investment. Integration can be optimal only when assets exhibit complementarity. When they do, transferring control of asset $a_{j}$ to party $i$ reduces party j's investment, but it simultaneously increases party $i$ 's incentive to invest, which means that the total trade surplus may be larger under type $i$ integration than under non-integration. Asset substitutability posits that the marginal benefit of investment decreases in the number of assets that a party controls. The case for joint control can be made when preventing a party from making use of assets outside the relationship boosts his incentive to invest.

Rajan and Zingales (1998) have pioneered the idea that asset ownership reduces the incentive to invest. Consider an economy in which production requires just one asset, and suppose

\footnotetext{
${ }^{19}$ Salvaggi (2009) disputes Cai (2003)'s conclusion for an economy in which i) a specialized widget has a market outside the relationship between the parties; ii) assets are strictly complementary, i.e. the marginal benefit of general investment is zero unless a party controls both assets. Because of strict complementarity of assets, there is no incentive to undertake general investment under joint control and non-integration alike. On the other hand, non-integration fosters specific investment as long as the value of the specialized widget on the outside market is increasing in specific investment. Condition ii) appears strong and it establishes an artificial equivalence between ownership regimes with respect to incentive to general investment.
} 
that investment takes the form of specializing human and physical capital for the production needs within the relationship. The owner of the asset is reluctant to undertake such an investment if it reduces the value of his outside option, which is the case when specialization precludes the owner from trading opportunities outside the relationship. Rajan and Zingales (1998) develop a framework in which rights to assets are of two types: the right to access the asset and the right to exclude others from accessing the asset. In the words of Hart and Moore (1990, p. 1150), the ability to exclude is the "the key right provided by ownership". Rajan and Zingales (1998) conclude that rights to exclude should be given to the non-investing party, while the investing party should be granted rights to access assets. A regime of joint control in which "no asset can be redeployed without the consent of the other party” (Rajan and Zingales 1998, p. 409) is akin to a situation in which no one has an outside option, and thus the incentive to invest is not adversely affected by ownership.

Bel (2013) extends the framework proposed in Rajan and Zingales (1998) to the case of many, intangible, rivalrous and non-rivalrous assets, over which parties can exchange access rights and veto rights. Parties form coalitions to produce with the assets that they have brought into the coalition. Exchanging veto right while preserving the right to access amounts to establish a regime of joint control. In presence of assets substitutability, exchanging veto rights fosters investments. Granting veto over an asset weakens the bargaining position of the party that bestows the right, but as long as assets are substitute, other partners' incentives to invest in the coalition are enhanced. Under the assumption that investments are complementary, each party's investment may increase, thus increasing the total surplus.

You First: Sequential vs. SimultaneOus InVEstments. Sequential investment is a distinctive feature of joint ventures in $R \& D$ intensive-industries. This stylized fact is at the heart of a small group of papers that investigate how joint control and conditional ownership (any ownership regime augmented with contractual clauses that specify options to own) promote efficiency when parties invest sequentially. We survey two contributions that address this issue, namely Noldeke and Schmidt (1998) and Lulfesmann (2004). Both depart from the GHM approach by introducing sequential investment and conditional ownership regimes. In this section, we discuss the optimality of joint control under the assumption of sequential investment, while we postpone the presentation of their results in the case of conditional ownership until Section 5.

Noldeke and Schimdt (1998) consider two parties that cooperate on a project to generate surplus $S$ by means of a single asset. Sequential ex-ante investments, characterized by spillovers across outside options, can increase the surplus. Unconditional ownership regimes comprise type $i$ integration and joint control. Noldeke and Schmidt (1998) do not rank these regimes, as their main focus is on conditional ownership. Still, for the purpose of the present survey, we notice that they illustrate the distortions associated with type $i$ integration and joint control in the presence of 
sequential ex-ante investments. Developing their argument, we argue that the ranking of ownership regimes is altered when parties invest sequentially. Let us assume that both parties invest in physical capital. ${ }^{20}$ First, consider simultaneous investments. Party $j$ does not invest under type $i$ integration; owning the asset, party $i$ fully benefits from party $j$ 's investment, even when not cooperating with him; party $i$ would thus reject any suggestion about sharing the production surplus with party $j$. Joint control fosters party $j$ 's investment but at the cost of a reduction in party i's investment. Suppose that the latter effect is so strong that the surplus is maximal under type $i$ integration. Type $i$ integration dominates joint control. Still, this ranking of regimes is not robust to the introduction of sequential investment. Let party $i$ invest first. In selecting his investment, party $i$ acts as a Stackelberg leader and considers how party $j$ will react to his investment choice. Under type $i$ integration, party $j$ does not invest, and thus party $i$ 's incentive to invest is unaffected with respect to simultaneous investment. Under joint control, party $j$ does invest. Thus, party $i$ may invest more when investing first than when investing simultaneously, which is the case when investments are complementary. Therefore, even if it is smaller than the surplus under type $i$ integration with simultaneous investments, the surplus under joint control may exceed the surplus under type $i$ integration when parties invest sequentially.

Lulfesmann (2004) argues that joint ownership promotes efficiency when parties investing sequentially can renegotiate the allocation of residual rights after party $i$ has invested but before party $j$ invests. In his paper, ownership confers exclusive rights on residual income, and party $j$ thus reaps no benefit from his own investment under type $i$ integration. Party $j$ invests only if ownership is renegotiated. Because of investment complementarity, when party $j$ fails to invest in the event of disagreement on ownership transfer, party i's outside option decreases, and his marginal incentive to invest is lessened. In a regime of joint ownership, party $j$ receives a share of surplus from investing even if transfer of ownership negotiations fail; thus, party $j$ 's outside option and incentive to invest improves with respect to type $i$ integration. Under investment complementarity, total surplus increases. Lulfesmann (2004) also compares the efficiency of joint control vs. conditional ownership. For this comparison, see Section 5.

More Than Once: What If PARTiEs RePeAtedly InVEst? The GHM approach focuses on one-off interactions among parties. Hart (1995) justifies this modelling choice in two ways. There are circumstances under which parties repeatedly trade, but investments are made just once. Repeated interactions allow the parties to support efficient outcomes through reputation. Still, "to develop a theory of the firm, one must analyze a situation where.... reputational forces are not strong enough to eliminate all problems of opportunism.” (Hart 1995, p. 67). What if reputational forces, albeit

\footnotetext{
${ }^{20}$ Alternatively, we could think of investments in an intangible excludable asset like a patent.
} 
present, are not so strong? Is there a role for ownership? A small set of papers ${ }^{21}$ addresses these questions and identifies joint control as the optimal allocation of property rights when parties trade repeatedly.

As the only departure from the GHM approach, Halonen (2002) considers an economy in which two parties live an infinite number of periods. In the first part of each period, parties invest simultaneously and independently; in the second part of each period, they use an asset $a$ to produce a final good. The total surplus from production depends on the parties' ex-ante investments and is divided via the Nash bargaining solution. The only contracts that parties can stipulate involve the allocation of property rights. In the very first period, before investing, parties select an ownership regime. $^{22}$ Given that there is just one asset, the choice is restricted to type $i$ integration and joint control. Halonen (2002) argues that the allocation of property rights affects the parties' ability to implement the first-best choice of investments in a repeated game. Repeated interactions allow the parties to sustain cooperation via the adoption of trigger strategies; parties cooperate until they observe a deviation, at which point, they revert to a non-cooperative strategy. Trigger strategies support cooperation as long as the benefits of deviating are fewer than the penalties that deviation entails. The benefits and the costs of deviating from the first-best levels of investment depend on the allocation of property rights. The deviation benefits are greater under joint control than under type $i$ integration. Partners have poorer outside options under joint control than under type $i$ integration. Under joint control, the deviating party can appropriate the most from the surplus generated through the first-best investment level of the non-deviating partner. As for costs, joint control delivers less overall investment than type $i$ integration; thus, it is associated with the largest surplus decrease with respect to the first-best level. Deviation benefits and costs move together across ownership regimes. Still, there are circumstances under which adopting a regime of joint control increases the net cost of deviations, which occurs when investment is inelastic with respect to the surplus share. Joint control ensures a large decrease in the surplus share; thus, it delivers the required punishment in terms of reduced investments and surplus.

Rosenkranz and Schmitz (2004) establish optimality of joint control for finitely repeated trades. They consider an economy in which two identical parties make perfect substitutable ${ }^{23}$ exante investments in a single physical asset over two subsequent periods or projects. Ownership regimes include type $i$ integration and joint control. Because of perfect substitutability, the uniqueness of equilibrium in each period investment game fails under joint control. This opens the door to cooperation, as the strategies adopted in subsequent periods can be made dependent on

\footnotetext{
${ }^{21}$ Albeit often cited as the first paper to study repeated trades, we do not include Garvey (1995) in this survey for it equates surplus sharing rules and control rights. As discussed in Section 2, this is not consistent with the GHM approach. See also Halonen (2002).

${ }_{22}$ The results generalize to the case in which parties can renegotiate the ownership regime in subsequent periods.

${ }^{23}$ Total surplus depends on total amount invested only.
} 
actions undertaken in the early stages of the game. The results extend to the case of renegotiable allocation of property rights.

IN A NUTSHELL: The optimality of joint control can be established by relaxing some of the assumptions of the GHM approach about investment. Joint control can dominate type $i$ integration and non-integration when (i) there are investment spillovers across outside options; (ii) parties can select among a number of investment actions, not all equally productive within the relationship and outside it; (iii) the marginal benefit of investment is decreasing in the number of assets that a party controls; (iv) investments are undertaken sequentially; and (v) parties repeatedly invest.

If conditions (iii), (iv) and (v) are alternative to the assumptions in the GHM approach, conditions (i) and (ii) give rise to models that nest GHM as a special case. It is worth noting that also in more general frameworks, the optimal ownership regime solves a problem of underinvestment. As joint control prevents parties from accessing their outside options, one would be tempted to conclude that it is optimal when parties overinvest under any other regime, which is not the case. When there are spillovers across outside options, parties refrain from investing to avoid improving their partner's bargaining position. When parties can choose between different types of investments, parties invest too much in the wrong sort of investment and too little in the right sort for any regime, except joint control.

\section{The Problem of EX-Post Bargaining}

A distinctive feature of the GHM approach is a focus on ex-ante inefficiencies, which accounts for the assumption that ex-post bargaining occurs under symmetric information and is efficient. Moreover, the division of ex-post surplus is modelled as a cooperative game via the Nash bargaining solution (Grossman and Hart, 1986; Hart, 1995) or the Shapley value (Hart and Moore, 1990). According to Grossman and Hart (1986) and Hart and Moore (1990), this choice entails no loss of generality, as the cooperative outcome is consistent with a number of non-cooperative bargaining games under the models' main informational assumptions. In this section, we ask: is there a role for joint control when the nature and rules of ex-post bargaining change?

SYMMETRIC VS. ASYMMETRIC INFORMATION. Schmitz (2008) introduces asymmetric information, postulating that parties do not observe their trading partner's outside option. When bargaining over the widget's price, they thus may fail to reach an agreement, which reduces their incentive to invest. Joint control of the only asset that is essential for production prevents the parties from accessing their outside options and thus neutralises the effects of asymmetric information on ex-post bargaining over the division of the trade surplus. ${ }^{24}$ Confident that they will reach an agreement, the

\footnotetext{
${ }^{24}$ Joint control may also prevent the parties from devoting resources to wasteful information gathering about outside options. See Schmitz (2006).
} 
parties invest more, and this investment increase may compensate for any decrease caused by the redistributional effects of a shift from type $i$ integration to joint control.

BEYOND THE NASH BARGAINING SOLUTION. In the GHM approach, the division of the trade surplus is the outcome of a cooperative game. As mentioned in Section 2, modelling the division of the trade surplus via the Nash bargaining solution means that each party receives his outside option plus a share of the extra surplus from trading within rather than outside the relationship. Despite being quite common in the literature (e.g., Halonen, 2002; Cai, 2003), referring to a party’s payoff outside the relationship as his outside option is a slight abuse of language, which masks an important conceptual distinction. In fact, there are two equally plausible interpretations of a party's disagreement payoff. Parties failing to reach an agreement continue negotiations, and while negotiating, they receive their disagreement payoff or inside option. Alternatively, the disagreement payoff is what a party receives when the negotiation breaks down and parties separate.

Chiu (1998) and de Meza and Lockwood (1998) ${ }^{25}$ show that the nature of the options available to the parties in the event of disagreement has far-reaching implications for ownership allocation. When disagreement payoffs are inside options, non-cooperative bargaining results in the same division of ex-post surplus as in the Nash bargaining solution, and GHM's claim that ownership motivates holds true. When disagreement payoffs are outside options, non-cooperative bargaining is governed by the outside option principle, by which the party with an outside option that exceeds his share of the trade surplus within the relationship only receives his outside option. ${ }^{26}$ Asset ownership that pushes a party's outside option above his trade surplus share demotivates rather than motivating investment. In fact, a party whose outside option is binding is not able to fully reap the benefits of his investment, as his payoff is capped by the value of his outside option. Chiu (1998) and de Meza and Lockwood (1998) conclude that there are relevant circumstances under which assets should be taken away to foster investments. ${ }^{27}$ The results in Chiu (1998) and de Meza and Lockwood (1998) have been interpreted (Schmitz, 2013b; Halonen, 2002) to lend support to the adoption of a regime of joint control. Still, de Meza and Lockwood (1998) confine themselves to ranking non-integration and type $i$ integration. Conversely, Chiu (1998) considers the case in which production requires the use of both assets and establishes the conditions under which non-integration is optimal. He proceeds to argue that these conditions also imply the optimality of

\footnotetext{
${ }^{25}$ These papers, written simultaneously and independently, deal with very similar issues; for this reason we discuss their main results jointly.

${ }^{26}$ To exemplify in relation to our stylized model: given the parties' investments, $M_{1}$ 's payoff is $r\left(e_{1} ; A_{1}\right)-C_{1}\left(e_{1}\right)$ if $r\left(e_{1} ; A_{1}\right) \geq \frac{1}{2}\left[R\left(e_{1}\right)+Q\left(e_{2}\right)\right]$

${ }^{27}$ de Meza and Lockwood (2004) study the implications of the outside option principle when there are investment spillovers across outside options and restore the GHM prediction.
} 
joint control. In fact, a regime of joint control can be construed as non-integration with strictly complementary assets, i.e., assets that are both indispensable for production.

The outside option principle applies when parties can unilaterally abandon negotiations. Manzini and Mariotti (2004) argue that, in many real-life situations, parties can only abandon negotiations and access their outside option by mutual consent. Joint ownership of physical assets is a case in point. Parties can only benefit from the most valuable use of a jointly owned asset outside the relationship by mutual consent. Manzini and Mariotti (2004, p. 945) describe the situation above through the notion of a joint outside option (JOO): "a JOO is just like a standard option... with the single difference that it can only be obtained if both players consent to take it." When there are frictions in bargaining frictions, ${ }^{28}$ the outcome of negotiations differs substantially in the presence of a JOO. Consider a situation in which parties can unilaterally abandon negotiations. By the outside option principle, the party with a binding outside option obtains at most this value. In the presence of a JOO, the same party receives a payoff in excess of his outside option, as he can block any attempt to terminate negotiations. Type $i$ integration and non-integration allow parties to unilaterally access their outside options; thus, ex-post bargaining is subject to the outside option principle. In a regime of joint control, the outside option principle fails to apply, and the incentive to invest by the party with the most favourable outside option may be enhanced. It follows that joint ownership can be preferred to any other regime on efficiency grounds.

EX-POST VS. EX-ANTE INEFFICIENCIES. In the GHM approach, ownership matters because it affects ex-ante investment. In the absence of ex-ante investments, the allocation of property rights still has efficiency implications. In Grossman and Hart (1987), prohibitively costly ex-post bargaining requires allocating control to the party whose payoff exhibits the highest variability across states of nature. However, in this early work, efficiency ranking of property rights regimes is confined to non-integration and type $i$ integration. In a recent series of papers, Hart and Moore $(2007,2008)$ and Hart (2008, 2009) return to consider inefficiencies in ex-post bargaining, arguing that they are essential for "more general and compelling theories of contracts and organizational form” (Hart and Moore, 2008, p. 3). In the newly developed framework, ${ }^{29}$ Hart (2009) indeed shows joint control to be optimal.

As with Hart (2009), consider an economy in which parties agree to trade a widget for price $p$ at some future date. At the time of contracting, there is uncertainty about the parties' benefits from trading with each other and about any other trading opportunities that either may have. Uncertainty is resolved before delivery, and parties may consider renegotiating unfavourable terms of trade. The parties only fully benefit from trade if their trading partners engage in some actions

\footnotetext{
${ }^{28}$ Manzini and Mariotti (2004) assume negotiation breaks down with positive probability at each round.

${ }^{29}$ For a thorough review of the contributions to this line of research, see Walker (2013).
} 
that are costless to them and helpful to the partner; ${ }^{30}$ threatening to withhold cooperation, a party can force renegotiation of the widget price. As it stifles relationships, renegotiation is costly; if they continue to trade, parties limit cooperation, ${ }^{31}$ and the total trade surplus decreases. Anticipating such costs, a party is ready to trade at the agreed upon price $p$ if the price is not "too unfavourable". Which price $p$ can prevent renegotiation and a loss of surplus? To answer this question, we enlist the help of $M_{1}$ and $M_{2}$ from Section 2. At some early date, $M_{1}$ and $M_{2}$ agreed to trade a widget at price $p$. Before the widget is delivered, $M_{1}$ 's valuation of the widget is revealed to be $v$, while $M_{2}$ 's cost of providing the widget is revealed to be $c$. Total surplus from trade is $(v-c)$. If trade occurs at a renegotiated price, the total surplus falls to $\theta(v-c)<(v-c)$, where $0<\theta<1$. Before delivery, the parties also learn the value of their outside option; if they separate, $M_{1}$ realizes $r$, while $M_{2}$ obtains $q$. In the event of renegotiation, assume that each party receives his outside option plus half of the surplus increase from trade with his long-term partner. It follows that $M_{1}$ is prepared to trade at price $p$ if and only if $p$ is low enough to ensure that his payoff from trading at that price exceeds his payoff from trading at a renegotiated price. ${ }^{32}$ In turn, $M_{2}$ does not initiate a renegotiation if and only if $p$ is high enough to ensure that he is better off trading at price $p$ rather than at any other renegotiated price. ${ }^{33}$ Renegotiation does not occur, and no surplus is lost if and only if the agreed upon price $p$ falls in an interval whose boundaries depend on the realisations of $M_{1}$ 's valuation of the widget $(v), M_{2}$ 's cost of providing the widget (c) and the parties' outside options ( $r$ and $q$ ). When contracting over $p$, parties know only the probability distribution of these variables. If they vary a lot, $p$ is likely to lie outside the non-renegotiation interval. Hart (2009) shows that asset ownership affects the likelihood of renegotiation through its impact on outside options' variability with respect to the trade surplus. If the degree of correlation between the values inside and outside the relationship depends on asset ownership, the allocation of property rights has efficiency implications. Suppose that asset control increases the correlation between the values inside and outside the relationship. Transferring control rights from $M_{2}$ to $M_{1}$ reduces the variability of the maximum price that $M_{1}$ is prepared to pay at the cost of increasing the variability

\footnotetext{
${ }^{30}$ These actions should not be mistaken for ex-ante investments. They are undertaken after uncertainty is resolved. To exemplify, consider the seller choosing a delivery time most convenient for the buyer.

${ }^{31}$ Adopting a behavioral perspective, Hart (2009) argues that a party is happy to help his partner as long as he feels well-treated. When faced with a renegotiation proposal, a party feels somehow deprived of his due, as determined by the terms negotiated in the initial contract. For a model where behavioral assumptions are interacted with the property rights theory of the firm, see also Fehr et al. (2007). In their work, joint ownership is shown to dominate type $i$ integration when agents investing sequentially in physical capital are heterogeneous in their concern for fairness.

${ }^{32} M_{1}$ refrains from initiating renegotiation if and only if $p \leq p_{M_{1}}=v-(1 / 2)[\theta(v-c)+(r-q)]$.

${ }^{33} M_{2}$ accepts to trade at price $p$ if and only $p \geq p_{M_{2}}=c+(1 / 2)[\theta(v-c)-(r-q)]$.
} 
of the minimum price that $M_{2}$ is prepared to accept. It follows that type 1 integration is optimal when $M_{1}$ 's payoff inside the relationship varies significantly with respect to $M_{2}$ 's trade surplus. Asset ownership can also decrease the correlation between values inside and outside the relationship. Suppose $v$ and $c$ are constant. It is plausible that a party will have more and better opportunities outside the relationship if he controls more assets. Taking away assets reduces the variability of outside options and the likelihood of renegotiation. Joint control achieves just that, as no party can access his outside option without the other's consent.

Both Grossman and Hart (1987) and Hart (2009) assume ex-post symmetric information. Ex-post inefficiencies materialise because there is no time to renegotiate (Grossman and Hart, 1987) or because renegotiation sours the relationship (Hart, 2009). Matouscheck (2004) develops a model in which parties bargain under asymmetric information about their payoffs from trade. Absent exante investments, ownership matters because parties bargain more aggressively when their disagreement payoffs are relatively large. Large disagreement payoffs reduce the probability of completing efficient trades. Under joint control, aggregate disagreement payoffs are the lowest, which minimizes the parties’ incentives to aggressively bargain. Parties select joint control when the expected benefits from completing efficient trades are substantial with respect to the surplus that they can realize outside the relationship.

Muller and Schmitz (2014) develop a model in which parties invest ex-ante and incur expost bargaining costs, thus departing from GHM's stage 1- and stage 3-assumptions (see Figure 1). After investments are sunk, parties must pay a fixed cost to start negotiation. If started, negotiation proceeds under symmetric information, and the trade surplus is divided according to the Nash bargaining solution. A party only incurs the transaction cost required to access negotiation if his share of the trade surplus exceeds the transaction cost. However, the trade surplus and thus each party's share of it depends on the magnitude of outside options. The larger the outside options, the smaller are gains from trade. It follows that party $j$ may not find it worthwhile to incur the transaction cost under type $i$ integration, although he is willing to do so under joint control. Anticipating that party $j$ fails to enter the negotiation stage under type $i$ integration, party $i$ has a stronger incentive to invest under a regime of joint control than under sole ownership.

Finally, Bai et al. (2004) derive the optimality of joint control in a model that departs from GHM, with respect to stage 1- and stage 3-assumptions. Indeed, they focus on the distinction between revenue shares and control rights and show their result's robustness to the introduction of ex-post inefficient bargaining. To economize on space, we present their basic model and its extensions in Section 5, to which we believe they make the most notable contribution.

IN A NUTSHELL: In the GHM approach, a party's trade surplus affects his incentive to invest. The total trade surplus depends on the efficiency of ex-post bargaining, while its division is sensitive to 
the rules that govern negotiations. When we depart from the assumption of symmetric information, ownership regimes differ in terms of the efficiency of ex-post bargaining that they allow the parties to achieve. If the parties have asymmetric information about their partner's outside option, under joint control parties bargain efficiently, as outside options play no role in negotiations. If parties must terminate negotiations to access their outside options and the so-called outside option principle applies, circumstances may arise in which a party that controls assets cannot obtain ex-post more than his outside option. When this situation occurs, assets should be taken away from investing parties, and a case for joint control has been made along this lines. The rules that govern bargaining may vary across ownership regimes. Contrary to any other regime in which parties unilaterally access their outside options, joint control can indeed be described as a situation in which parties can only access their outside options by mutual consent, which strengthens the bargaining position of the party with the most favourable outside option and enhances his incentive to invest. In the absence of ex-ante investment, ownership still matters. If they have private information about trade benefits, parties bargain less aggressively and are more likely to reach an agreement under joint control, as the values of their outside options are the lowest. As the benefits from trade within and outside the relationship diverge, parties grow unsatisfied with the agreed terms of trade and are prone to initiate costly renegotiations. Control rights affect the correlation between a party's benefits from trade within and outside the relationship. If taking away assets reduces the divergence between a party's benefits from trade within and outside the relationship, joint control dominates sole ownership. In an environment in which parties invest ex-ante and incur fixed transaction costs to initiate ex-post bargaining, the regime with the least attractive outside options fosters investment the most, as the gains from trade are more likely to exceed the transaction costs, and the parties are more likely to reach the negotiation stage. It follows that joint control dominates type $i$ integration in the presence of fixed bargaining costs.

\section{Incomplete Contracts and the Allocation of Property Rights}

Incomplete contracts are at the heart of the GHM approach. Ex-ante investments and ex-post benefits from trade are non-contractible, while residual rights of control are. Parties cannot commit themselves to specific courses of action for ex-ante investment or for the terms of ex-post trade. Instead, they can contractually assign authority over assets that are essential for production so that any ex-post disagreement on their usage is settled only with the consent of the party holding control rights. Coupled with the assumption that parties have no liquidity constraints, the contractibility of control rights makes it possible for the parties to cooperatively select the ownership regime. Still, parties are constrained in their choice to unconditional ownership regimes, whereby contracts specifying options to buy or sell control rights are ruled out, as explained in Grossman and Hart 
(1986). In this section we ask: how sensitive is the ranking of ownership regimes to the rules governing the allocation of property rights?

NON-COOPERATIVELY: JOINT CONTROL VS. OUTSIDE OWNERSHIP. In the GHM approach, the optimal allocation of property rights balances the benefit of promoting party i's investment with the cost of discouraging party j's investment. The underlying assumption is that both parties contribute to the generation of surplus. It follows that a party that does not contribute to the surplus should own no asset. Consider an economy in which there is only one asset, $a$. The production of a final good requires cooperation by both party $i$ and $j$ and the use of the asset. Introduce a third party in the economy, party $k$. Party $k$ adds nothing to the surplus that is generated through $i$ and $j$ 's cooperation and, in keeping with Hart and Moore (1990), we refer to him as the outside party. Asset ownership can be assigned to any party in the economy. Under type $i$ integration, the investing parties both receive half of the trade surplus, while $k$ receives zero. Under type $k$ integration, the investing parties each receive a third of the trade surplus, with $k$ obtaining the remaining third. Production can occur only with the use of asset $a$; thus, the investing parties must share the production surplus with $k$. Under type $k$ integration, the incentive to invest is diluted for the investing parties, and total surplus decreases with respect to other types of integration. As mentioned above, the parties suffer no liquidity constraints in the GHM approach, and they can cooperatively select the ownership regime; outside ownership is never to be observed.

Von Lilienfeld-Toal (2003) argues that even if it is never observed, the simple threat of outside ownership alters the regime ranking. Suppose that asset $a$ is owned by $M_{1}$. After investments are sunk and before beginning negotiations with $M_{2}$ about the widget's price, $M_{1}$ can make a take-or-leave-it offer to an outside party $M$ for asset $a$. $M$ has no investment opportunity for his personal wealth, except of he enters a coalition with $M_{1}$ and $M_{2}$; thus, he is prepared to pay $M_{1}$ a sum that equals one-third of the surplus from the production of the final good. The threat to sell is credible as long as $M_{1}$ is better off receiving two-thirds of the surplus that is generated in the new coalition - in which his own and $M_{2}$ 's incentives to invest are diluted - than he is in receiving half of the surplus under type 1 integration. When this threat exists, bargaining over the widget's price leaves $M_{2}$ with a third of the trade surplus and a lessened incentive to invest. In a regime of joint control, the threat to sell is empty, as no party can dispose of the asset without the consent of the other. It follows that the incentive to invest is greater for $M_{2}$ under joint control than under type 1 integration. Despite the decrease in party 1's investment, joint control may deliver a larger surplus than type 1 integration and thus be preferred to the latter. As mentioned in Von Lilienfeld-Toal (2003), the optimality of type $i$ integration in the GHM approach rests on the fact that the non-owner's incentive to invest is the same under type $i$ integration and joint control, which 
results from the asset market closing before parties invest. If the parties can access the market for assets after investments are sunk, the non-owner's incentive to invest increases when switching from type $i$ integration to joint control.

Gans (2005) argues that outside ownership is the equilibrium outcome when a large number of investing and outside parties participate in a market in which ownership is allocated noncooperatively. Suppose that residual rights of control are allocated via an auction. Even as nonowners, productive or investing parties can command a share of the total surplus. In fact, production requires their contributions, which is not the case for an outside party that, by definition, contributes nothing to the surplus and thus can only obtain a share as an owner. It follows that outside parties are prepared to pay a higher price for residual rights of control than investing parties; thus, outside ownership results. Outside ownership could be blocked by a coalition of investing parties, which would then internalize the consequences of outside ownership on each party's incentive to invest. Still, joint bidding is only sustainable if it leads to joint ownership. If asset ownership is assigned according to which investing party’s contribution matters most in surplus generation, outside ownership will soon prevail. Only joint ownership — albeit inefficient compared with type $i$ integration - can prevent a single owner from expropriating the other investing parties by selling the asset to an outside party.

Revenue Shares vs. CONTROL Rights. In the GHM approach, ex-post trade benefits are noncontractible, which rules out revenue sharing contracts as a means to provide incentives for ex-ante investment. Still, there are circumstances under which even allowing the parties to contract over the division of the ex-post surplus may fail to induce efficient ex-ante investment. When this is the case, joint control proves to be the optimal ownership regime. Broadly sketched, this is the point made in both Bai et al. (2004) and Wang and Zhu (2005). ${ }^{34}$ Suppose $M_{1}$ and $M_{2}$ cooperate on a project to produce a final good by an asset. Upon completion, the project generates verifiable income and unverifiable private benefits to the parties. The magnitude of verifiable income and private benefits depends on the asset's specific deployments. The party in control of the asset can put the asset to use in ways that increase his private benefit at the cost of reducing both the project's income and the non-owner's private benefit. It follows that type $i$ integration carries with it a risk of expropriation for the non-owner. To avoid the materialisation of this expropriation, party $i$ should receive such share of the verifiable income, that the increase in his private benefit falls short of the loss he suffers due to the reduction in verifiable income. When private benefits from specific asset usage are substantial, even a large share of the verifiable income may not prevent the expropriation of the non-owner and adverse effects on his ex-ante investments. Joint control limits party i's discretion and restores party $j$ 's incentive to invest; thus, the total surplus under joint control may

\footnotetext{
${ }^{34}$ These papers deal with very similar issues; for this reason we discuss their main results jointly.
} 
exceed that of type $i$ integration. ${ }^{35}$ Bai et al. (2004) also show that an expropriation risk entails the optimality of joint control when there are no ex-ante investments and ex-post renegotiation is prohibitively costly. Interestingly, this paper also provides empirical evidence that supports the view that revenue shares and control rights are not substitute. The authors examine over 200 joint venture contracts involving a Chinese partner and report that many decisions require a qualified majority or unanimity, no matter the allocation of equity shares between partners. ${ }^{36}$

CONDITIONAL OWNERSHIP. In the GHM approach, the optimal allocation of property rights minimizes distortions in ex-ante investment but fails to achieve the first best. Noldeke and Schmidt (1998) and Maskin and Tirole (1999) are the first to argue that first-best investment can indeed be obtained by means of ownership regimes that are only slightly more complex than the GHM unconditional ones.

Noldeke and Schmidt (1998) show that in the case of sequential ex-ante investments, the first best can be achieved by assigning sole ownership to the party that invests first — let it be $M_{1}$ — and granting a call option to the party that invests second - let it be $M_{2}$. An appropriate choice of the exercise price makes it optimal for $M_{2}$ to exercise the option only if $M_{1}$ invests at the first best level. As the asset is of little value to $M_{1}$ without the contribution of $M_{2}, M_{1}$ invests to induce $M_{2}$ to exercise his option. As a sole owner, $M_{2}$, in turn, invests optimally. Although Noldeke and Schmidt (1998) describe the ownership regime outlined above as common in joint ventures, it cannot be considered a regime of joint ownership.

Maskin and Tirole (1999) show that the first best can be achieved in a regime of joint control that is supplemented with (i) an option to sell property rights at a specified price, after investments are sunk, and (ii) a penalty to be paid to a third party, when the option is exercised. Suppose $M_{1}$ and $M_{2}$ jointly own an asset. $M_{1}$ holds the right to sell his share of the asset at price $p_{1}$, while the exercise price for $M_{2}$ 's put option is $p_{2}$. After investments are sunk, either $M_{1}$ or $M_{2}$ is randomly selected to exercise his put option. Exercise prices can be selected so that each party finds it optimal to sell his share of the asset if the partner invested below the first best. Threatened with a large enough penalty, parties invest efficiently. While put and call options are a

\footnotetext{
${ }^{35}$ Hauswald and Hege (2003) apply a similar argument in explaining the prevalence of 50-50 equity share allocation in joint venture contracts. Majority holdings reward resource contributions as well as granting private but socially costly benefits.

${ }^{36}$ Focusing on expropriation risk, Tao and Wu (1997) develop an argument in support of joint control in the context of inter-firm R\&D cooperation and provide empirical evidence consistent with their conclusion. As Bai et al. (2004), Dasgupta and Tao (1998) argue that revenue shares and ownership rights are not substitute in providing incentive to invest. In their view, ownership provides superior incentive to invest with respect to revenue sharing agreements for only ownership confers alienable rights on income flows. However, focusing on the rights on income flows, Dasgupta and Tao (1998) move outside PRT.
} 
common feature of joint ventures agreements, penalties paid to third parties are "rarely observed in practice” (Maskin and Tirole, 1999, p. 144). In the absence of penalties, the first best can no longer be achieved, and alternative ownership regimes (e.g., the random allocation of property rights after investments are sunk) provide the same incentive to invest as does joint control.

Lulfesmann (2004) compares joint control and conditional ownership regimes under the assumption of sequential ex-ante investment. Sole ownership by the party investing first, supplemented with a call option granted to the party investing second, is only shown to dominate joint control when investment complementarity is low.

Finally, Annen (2009) observes that under joint control, the resolution of disagreements over asset usage often entails legal recourse or arbitration. The allocation of ownership rights through third parties takes the form of a contest, the outcome of which depends on the amount of resources devoted to it. The greater the benefit from acquiring control of the asset, the more resources a party is prepared to devote to the contest. As the benefit from controlling the asset increases in ex-ante investments, the parties invest to signal their commitment to fight for the asset ex-post, which makes the trade surplus larger under joint control than any other regime.

IN A NUTSHELL: Under joint control, neither party has discretion in the deployment of assets, which fosters ex-ante investment as long as sole ownership of the asset brings with it an expropriation risk for the non-owner. In GHM, ownership regimes are selected cooperatively, and parties that do not contribute to the surplus have no control rights. In a non-cooperative allocation of control rights, outside ownership cannot be ruled out, and the dilution of the trade benefit adversely affects ex-ante investment. Joint control by all agents contributing to the surplus prevents outside ownership. An expropriation risk for the non-owner also arises when the controlling party enjoys private benefits from specific asset usage at the expense of verifiable trade revenues. When private benefits are substantial, even a large revenue share for the controlling party cannot prevent expropriation, and the parties must resort to joint control. In GHM, the allocation of control rights is unconditional, i.e., ownership cannot be transferred conditional on ex-ante investment. Supplemented with a put option on the assets, joint control allows the parties to reallocate ownership rights ex-post, and it thus fosters ex-ante investment to prevent the exercise of the option. Finally, it is only under joint control that parties must engage in a contest to allocate control rights in the event of ex-post disagreement. As long as success in the contest depends on ex-ante investment, joint control delivers a larger surplus than any other regime.

[Insert Figure 2 about here] 


\section{ConCLuSiOnS}

In this paper, we review the contribution of the property rights theory of the firm to our understanding of joint ventures. Under the standard GHM assumptions, a regime of joint control is never optimal, and thus, no firm would choose it. This premise is the beginning of our work. In Section 2, we describe the GHM approach, and, considering the costs and benefits of integration, we derive the famous result about suboptimality of JV. In Section 3, 4 and 5 we survey more than 20 papers that remove (at least one of) the GHM assumptions, proving the optimality of JVs under contractual incompleteness in the context of the PRT. Consistent with the timing of events in the GHM game, we group the surveyed contributions into three main categories, depending on the questioned assumption(s). In Section 3, we present papers dealing with the nature of the investment. In Section 4, we present papers about the problem of ex-post bargaining, and Section 5 is completely devoted to contracts and the allocation of property rights.

As displayed in Figure 2, the nature of investment is the issue that has received the most attention so far. Indeed, 11 papers fall into this class, proving that joint control can dominate other ownership regimes when (i) there are investment spillovers across outside options; (ii) parties can select among a number of investment actions; (iii) the marginal benefit of investment is decreasing in the number of controlled assets; (iv) investments are undertaken sequentially; and ( $v$ ) parties repeatedly invest. Clearly, the aforementioned departures from the original framework do not carry the same modelling weight. While conditions (iii), (iv) and (v) are alternatives to the GHM assumptions, conditions (i) and (ii) give rise to more general models that nest GHM as a special case.

Contracts and the allocation of property rights are the second most debated issue in the literature, as it has been discussed in 8 of the surveyed papers. Contributions falling into this class generally restore the optimality of JVs by considering (i) a non-cooperative setting; (ii) conditional ownership; and (iii) the distinction between revenue shares and control rights. In models based on (i) and (iii), joint control is desirable, as it fosters ex-ante investment when sole ownership implies an expropriation risk for the non-owner. Authors that elaborate on (ii) instead suggest that joint control be supplemented with a put option that allows the parties to reallocate ownership rights expost and thus promote ex-ante investment.

Lastly, only 7 of the surveyed contributions address the problem of ex-post bargaining by (i) assuming asymmetric information; (ii) going beyond the Nash bargaining solution or (iii) more radically showing that absent ex-ante investment, joint control minimizes ex-post inefficient renegotiations and favours expedited agreements. To understand why JVs turn out to be optimal in this contest, one can think as follows. In GHM, a party's incentive to invest is crucially shaped by his share of the trade surplus. In addition, the total surplus from trade depends on the efficiency of 
ex-post bargaining, while its division is sensitive to the rules under which negotiation takes place. If the parties have asymmetric information about their partner's outside option, joint control ensures efficient bargaining, as outside options play no role in negotiations. If parties must instead terminate negotiations to access their outside options and the so-called outside option principle applies, the party in control of the asset may not obtain more than his outside option ex-post. In this case, assets should be taken away from investing parties, and joint control may emerge as the optimal choice. In the absence of ex-ante investment, ownership still matters. As the benefits from trade within and outside the relationship diverge, parties grow unsatisfied with the agreed-upon terms of trade and are prone to initiate costly renegotiations. Control rights affect the correlation between a party's benefit from trade within and outside the relationship. When taking away assets reduces the divergence between a party's benefit from trade within and outside the relationship, joint control outperforms sole ownership. Joint control is optimal also when, in the absence of ex-ante investment, parties have private information about trade benefits.

Reading the 24 papers chartered in Figure 2 is a journey through the establishment and evolution of an economic paradigm. The seminal contributions of Grossman and Hart (1986) and Hart and Moore (1990) apparently had no room for joint control, and for some time, the matter rested there. Subsequently, scattered in time and bibliographical space, a number of contributions have begun to appear, rising to the challenge posed by the widespread adoption of joint control as a governance mode. All of the lines of thought developed in these contributions have shed light on the diffusion of JVs. However, some of lines of thought appear to stand out in capturing the benefits and costs of joint control. Investment spillovers across outside options, discretion in directing resources toward general rather than specific investments, and finally, ex-post inefficiencies are in our view building blocks for the general theory of the firm, which the GHM approach set out to build in the late 1980s. Interestingly, these ideas are either reminiscent of some aspect of the GHM approach, which have been neglected in the subsequent literature, such as the idea of overinvestment, or are due to the most recent work of Hart himself. Thus, those who started the debate seem also to have the last word on the topic. ${ }^{37}$

In light of the above discussion, can we conclude that the PRT offers a satisfactory explanation of the widespread adoption of joint ownership? A careful inspection of the surveyed papers suggests that there are still some gaps in the formal treatment of JV contracts and that steps to fill those gaps need to be taken. In the following, we briefly illustrate a few of these steps.

As mentioned above, we see spillovers across outside options, multidimensional investment and ex-post inefficiencies as key to provide a rationale for joint control. Despite evident potential

\footnotetext{
${ }^{37}$ This is not to be interpreted from a chronological perspective, but rather according to a history of economic thought perspective.
} 
interactions, no model considers these elements jointly. Future researches may address questions such as: how would ex-post inefficiencies affect the choice of ex-ante multidimensional investment? Could general investments be the trigger of inefficient ex-post renegotiations?

Other and more interesting challenges come from the field of international economics. The models discussed in Sections 3, 4 and 5 share a common feature: for analytical convenience, they consider only a bilateral framework in which two parties choose the ownership regime among type $i$ integration, non-integration and joint control. Having only two agents is sufficient to derive some basic results on the optimality of a given allocation of property rights. Nevertheless, a multilateral framework would enable a deeper inspection of the costs and benefits of integration and a more realistic treatment of the firms' behaviour. When there are only two firms, matching is taken for granted; in a context of $n$ firms, it would be extremely interesting to study how pairs are formed at the beginning of the game. While McLaren (2000) and Grossman and Helpman (2002) pioneered this line of research, extending $\mathrm{GHM}^{38}$ to allow for multilateral relations among agents, they only modelled the choice between type $i$ integration and non-integration, without paying attention to the JVs. Importantly, the firms' heterogeneity à la Melitz (2003) ${ }^{39}$ could also be added as a crucial ingredient to the above recipe because it is reasonable to assume that JV partners are different so that they can pool complementary skills. In our view, proceeding in this manner would eventually deliver two notable outcomes. From a theoretical perspective, it would pave the way to a crucial extension of the Antras and Helpman (2004, 2008) famous taxonomy of ownership regimes as shaped by the domestic vs. international allocation of property rights. To date, such taxonomy only includes domestic integration, foreign integration, domestic non-integration and foreign nonintegration. ${ }^{40}$ Firms choose one of the above regimes in a model in which crucial assumptions rest on the GHM game and Melitz heterogeneity. Adding JV to the Antras and Helpman (2004, 2008) taxonomy would result in a more comprehensive characterization of global sourcing and a better understanding of the international strategies of firms. From an empirical perspective, the availability of large longitudinal databases would allow for an original analysis of performance differentials among firms selecting alternative ownership regimes. Starting from the seminal contribution of

\footnotetext{
${ }^{38}$ For a survey on the application of GHM to the international background, see Spencer (2005), Antras and RossiHansberg (2009) and Antras (2014).

39 Melitz (2003) models the relationship between industry exposure to international trade and its structure and performance, allowing for intra-industry heterogeneity across firms. He demonstrates that the exposure to international trade results in more productive firms to export and less productive firms to exit the market. A further increase in industry exposure to trade induces an intra-industry reallocation in favour of more productive firms. This explains why international trade may generate aggregate productivity gains without necessarily improving the efficiency of individual firms. The core Melitz (2003) model has been recently developed in various ways to give rise to a well-established body of theories on heterogeneous firms and trade. For a survey, see Redding (2011).

${ }^{40}$ An attempt of this sort has been pioneered by Cui (2011). This article theoretically explores the effects of foreign ownership restrictions on the firms' choice of market entry and its welfare implications. To do so, the author revisits Antras and Helpman's (2004) definition of integration to embrace sole ownership and joint ownership, as opposed to non-integration.
} 
Bernard and Jensen (1995), scholars worldwide have begun to investigate the relationship between internationalization and performance at the microeconomic level. ${ }^{41}$ Interestingly, they document that globally engaged enterprises tend to be a minority compared with purely domestic firms, but they perform better on a number of economic, innovation and financial variables. While internationalization is mostly measured in terms of import, export and foreign direct investment (FDI), we are not aware of any study addressing the joint venture premiums, except for Raff et al. (2008), that embed (international) JV under the general case of FDI.

${ }^{41}$ For a survey on this topic, see: Lopez (2005), Wagner (2007, 2012), Greenaway and Kneller (2007), Singh (2010) and Hayakawa et al. (2012). 


\section{REFERENCES}

Aghion P. and Holden, R. (2011) Incomplete contracts and the theory of the firm: what have we learned over the past 25 years?. Journal of Economic Perspectives 25: 181-197.

Annen, K. (2009) Efficiency out of disorder: contested ownership in incomplete contracts. RAND Journal of Economics 40: 597-610.

Antras, P. (2014) Grossman-Hart (1986) goes global: incomplete contracts, property rights, and the international organization of production. Journal of Law, Economics and Organization 30: 118175.

Antras, P. and Helpman, E. (2004) Global sourcing. Journal of Political Economy 112: 552-580.

(2008) Contractual frictions and global sourcing. In E. Helpman, D. Marin, and T.

Verdier (eds.) The Organization of Firms in a Global Economy (pp. 9-54). Cambridge: Harvard University Press.

Antras, P. and Rossi-Hansberg, E. (2009) Organizations and Trade. Annual Review of Economics 1: 43-64.

Bai, C., Tao, Z., and Wu, C. (2004) Revenue sharing and control rights in team production: theories and evidence from joint ventures. RAND Journal of Economics 35: 277-305.

Bel, R. (2013) Access, veto, and ownership in the theory of the firm. Journal of Law, Economics, and Organization 29: 871-897.

Bernard, A. and Jensen, J.B. (1995). Exporters, jobs and wages in US manufacturing: 1976-1987. Brookings Papers on Economic Activity, Microeconomics: 67-119.

Cai, H. (2003). A theory of joint asset ownership. RAND Journal of Economics 34: 63-77.

Caloghirou, Y., Ioannides, S. and Vonortas, N.V. (2003) Research joint ventures. Journal of Economic Surveys 17: 541-570.

Chiu, Y.S. (1998) Noncooperative bargaining, hostages, and optimal asset ownership. American Economic Review 88: 882-901.

Cui, F. (2011) Incomplete contracts, joint ventures, and ownership restrictions. Oxford Economic Papers 63: 254-278.

Dasgupta, S. and Tao, Z. (1998) Contractual incompleteness and the optimality of equity joint ventures. Journal of Economic Behavior and Organization 37: 391-413.

Fares, M. (2006) Renegotiation design and contract solutions to the hold-up problem. Journal of Economic Surveys 20: 731-756.

Fehr, E., Kremhelmer, S. and Schmidt, K.M. (2007) Fairness and the optimal allocation of ownership rights. Economic Journal 118: 1262-1284.

Foss N.J., Lando, H. and Thomsen, S. (2000) The theory of the firm. In B. Bouckaert and G. De Geest (eds.) Encyclopedia of Law and Economics vol. 3 (pp. 631-658). Cheltenham U.K.: Edward Elgar Publishing Ltd. 
Gans, J.S. (2005) Markets for ownership. RAND Journal of Economics 36: 433-445.

Garvey, G.T. (1995) Why reputation favors joint ventures over vertical and horizontal integration. A simple model. Journal of Economic Behavior and Organization 28: 387-397.

Gibbons, R. (2005) Four formal(izable) theories of the firm?. Journal of Economic Behavior and Organization 58: 200-245.

Greenaway, D. and Kneller, R.A. (2007) Firm heterogeneity, exporting and foreign direct investment: a survey. Economic Journal 117: F134-F161.

Grossman, S. and Hart, O. (1986) The costs and benefits of ownership: a theory of vertical and lateral integration. Journal of Political Economy 94: 691-719.

(1987) Vertical integration and the distribution of property rights. In A. Razin and E. Sadka (eds.) Economic Policy in Theory and Practice (pp. 504-548). London: Macmillan Press.

Grossman, S.J. and Helpman, E. (2002) Integration versus outsourcing in industry equilibrium. Quarterly Journal of Economics 117: 85-120.

Guriev, S. (2003) Incomplete contracts with cross-investments. Contributions to Theoretical Economics 3: Article 5.

Hagedoorn, J. (1996) Trends and patterns in strategic technology partnering since the early seventies. Review of Industrial Organization 11: 601-616.

Hagedoorn, J. (2002) Inter-firm R\&D partnerships - an overview of major trends and patterns since 1960. Research Policy 31: 477-492.

Halonen, M. (2002) Reputation and the allocation of ownership. Economic Journal 112: 539-558.

Hart, O. (1995) Firms Contracts and Financial Structure. Oxford: Oxford University Press.

(2008) Economica Coase lecture: reference points and the theory of the firm.

Economica 75: 404-411.

(2009) Hold-up, asset ownership, and reference points. Quarterly Journal of Economics 124: 267-300.

Hart, O. and Moore, J. (1990) Property rights and the nature of the firm. Journal of Political Economy 98: 1119-1158.

(2007) Incomplete contracts and ownership: Some new thoughts. American Economic Review 97: 182-186.

(2008) Contracts as reference points. Quarterly Journal of Economics 123: 1-48.

Hauswald, R. and Hege, U. (2003) Ownership and control in joint ventures: Theory and evidence. CEPR Discussion Papers: 4056.

Hayakawa, K., Machikita, T. and Kimura, F. (2012) Globalization and productivity: a survey of firm-level analysis. Journal of Economic Surveys 26: 332-350. 
Kogut, B. (1988) Joint ventures: theoretical and empirical perspectives. Strategic Management Journal 9: 319-332.

Lafontaine, F. and Slade, M. (2007) Vertical integration and firm boundaries: the evidence. Journal of Economic Literature 45: 629-685.

von Lilienfeld-Toal, U. (2003) Asset ownership and the threat to sell. Journal of Economics (Zeitschrift Fur Nationalokonomie) 80: 1-25.

Lopez, R.A. (2005) Trade and growth: reconciling the macroeconomic and microeconomic evidence. Journal of Economic Surveys 19: 623-648.

Lulfesmann, C. (2004) Research collaborations with sequential investments. Economica 71: 241259.

Lyons, M.P. (1991) Joint-ventures as strategic choice: a literature review. Long Range Planning 24: 130-44.

Manzini, P. and Mariotti, M. (2004) Going alone together: joint outside options in bilateral negotiations. Economic Journal 114: 943-960.

Martimort, D., De Donder, P. and de Villemeur, E. B. (2005) An incomplete contract perspective of public good provision. Journal of Economic Surveys 19: 149-180.

Maskin, E. and Tirole, J. (1999) Two remarks on the property-rights literature. Review of Economic Studies 66: 139-149.

Matouschek, N. (2004) Ex-post inefficiencies in a property rights theory of the firm. Journal of Law, Economics and Organization 20: 125-147.

McLaren, J. (2000) Globalisation and vertical structure. American Economic Review 90: 12391254.

de Meza, D. and Lockwood, B. (1998) Does asset ownership always motivate managers? Outside options and property rights theory of the firm. Quarterly Journal of Economics 113: 361-386.

(2004) Spillovers, investment incentives and the property rights theory of the firm. Journal of Industrial Economics 52: 229-253.

Melitz, M.J. (2003) The impact of trade on intra-industry reallocations and aggregate industry productivity. Econometrica 71: 1661-1694.

Moskalev, S.A. and Swensen, B.R. (2007) Joint ventures around the globe from 1990-2000: forms, types, industries, countries and ownership patterns. Review of Financial Economics 16: 29-67.

Muller, D. and Schmitz, P.W. (2014) Transaction costs and the property rights approach to the theory of the firm. CEPR Discussion Papers: 10207.

Noldeke, G. and Schmidt, K.M. (1998) Sequential investments and options to own. RAND Journal of Economics 29: 633-653.

Raff, H., Ryan, M. and Stahler, F. (2008) Firm productivity and the foreign-market entry decision. Kiel University, Department of Economics Working Paper: 2. 
Rajan, R.G. and Zingales, L. (1998) Power in the theory of the firm. Quarterly Journal of Economics 113: 361-386.

Redding, S.J. (2011) Theories of heterogeneous firms and trade. Annual Review of Economics 3: 77-105.

Rosenkranz, S. and Schmitz, P.W. (1999) Know-how disclosure and incomplete contracts. Economics Letters 63: 181-185.

(2003) Optimal allocation of ownership rights in dynamic R\&D alliances. Games and Economic Behavior 43: 153-173.

(2004) Joint ownership and incomplete contracts: the case of perfectly substitutable investments. Schmalenbach Business Review 56: 72-89.

Salanie, B. (1997) The economics of contracts. Cambridge, Mass: MIT Press.

Salvaggi, M. (2009) Optimal vertical arrangements when resale is possible. Journal of Law, Economics and Organization 25: 211-234.

Schmitz, P.W. (2001) The hold-up problem and incomplete contracts: A survey of recent topics in contract theory. Bulletin of Economic Research 53: 1-17.

(2006) Information gathering, transaction costs, and the property rights approach. American Economic Review 96: 422-434.

(2008) Joint ownership and the hold-up problem under asymmetric information. Economics Letters 99: 577-580.

(2013a) Bargaining position, bargaining power, and the property rights approach. Economics Letters 119: 28-31.

(2013b) Investments in physical capital, relationship-specificity, and the property rights approach. Economics Letters 119: 36-339.

Segal, I. and Whinston, M.D. (2012). Property rights. In R. Gibbons and J. Roberts (eds.) Handbook of Organizational Economics (pp. 100-158). Princeton: Princeton University Press.

Singh, T. (2010) Does international trade cause economic growth? A survey. The World Economy 33: $1517-1564$.

Spencer, B.J. (2005) International outsourcing and incomplete contracts. Canadian Journal of Economics 38: 1107-1135.

Tao, Z. and Wu, C. (1997) On the organization of cooperative R\&D: theory and evidence. International Journal of Industrial Organization, 15: 573-596.

Tirole, J. (1999) Incomplete contracts: where do we stand?. Econometrica 67: 741-781.

UNCTAD (2014) http://unctad.org/en/Pages/DIAE/Investment\%20and\%20Enterprise/JointVenture.aspx 
Wagner, J. (2007) Exports and productivity: a survey of the evidence from firm-level data. The World Economy 30: 60-72.

Wagner, J. (2012) International trade and firm performance: a survey of empirical studies since 2006. Review of World Economics 148: 235-267.

Walker, P. (2013) The "Reference Point" approach to the theory of the firm: an introduction. Journal of Economic Surveys 27: 670-695.

(2014) Contracts, entrepreneurs, market creation and judgment: the contemporary mainstream theory of the firm in perspective. Journal of Economic Surveys doi: 10.1111/joes.12058.

Wang, S. and Zhu, T. (2005) Control allocation, revenue sharing, and joint ownership. International Economic Review 46: 895-915.

Werner, S. (2002) Recent developments in international management research: a review of 20 top management journals. Journal of Management 28: 277-305.

Williamson, O.E. (2002) The theory of the firm as governance structure: from choice to contract. Journal of Economic Perspectives 16: 171-195.

Zephyr (2014), Comprehensive M\&A data with detailed company information, http://www.unibocconi.it 
Figure 1: Time line of GHM

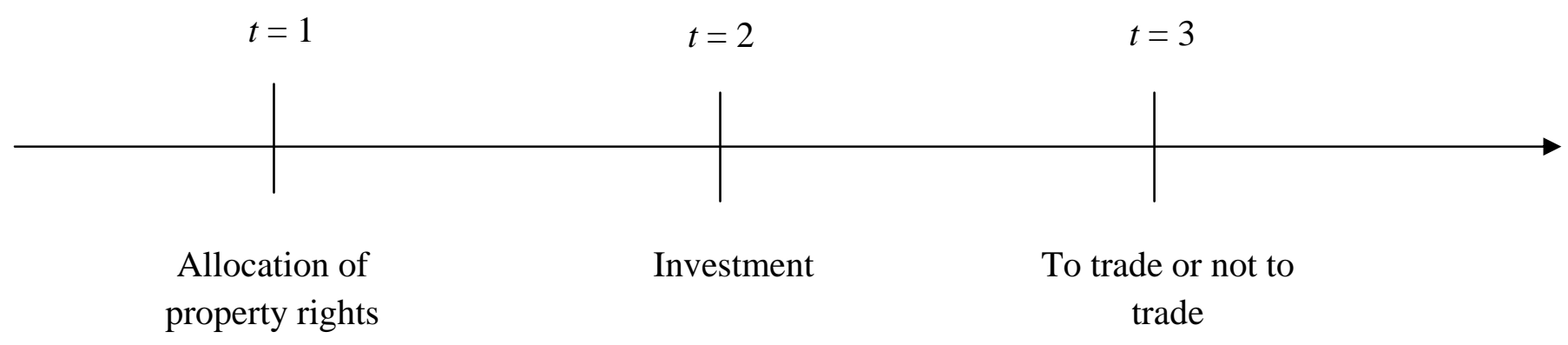


Figure 2: The optimality of JV, by departure from GHM
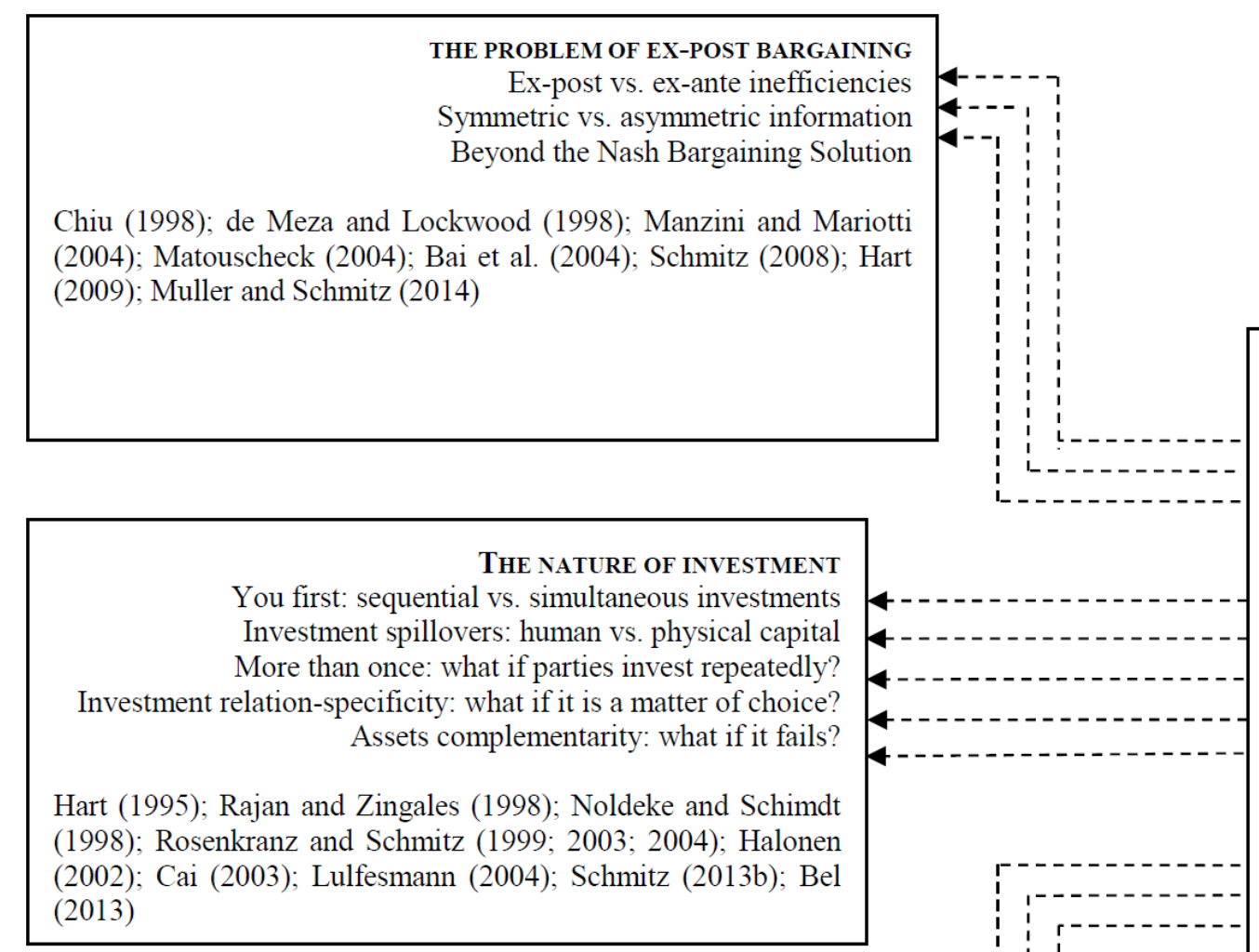

stage 3: Trade or not to trade

GHM

Bargaining is efficient

Bargaining occurs under symmetric information

The surplus from trade is shared according to the Nash Bargaining Solution

\section{stage 2: Investment}

The two parties invest simultaneously

Investment is in human capital

Investment is made only once

Investment is relation-specific

Assets are either complement or independent, never substitute

stage 1: Allocation of property rights

Parties meet and select cooperatively the ownership regime

Ownership regimes are unconditional

|

Ownership confers jointly control rights and residual rights on income

INCOMPLETE CONTRACTS \& THE ALLOCATION OF PROPERTY RIGHTS

Non-cooperatively: joint control vs. outside ownership Conditional ownership

Revenue shares vs. control rights

Noldeke and Schmidt (1998); Maskin and Tirole (1999); Von Lilienfeld-Toal (2003); Bai et al. (2004); Lulfesmann (2004); Wang and Zhu (2005); Gans (2005); Annen (2009) 